\title{
ASSESSMENT OF MECHANICAL PROPERTIES OF HIGH STRENGTH CONCRETE (HSC) AFTER EXPOSURE TO HIGH TEMPERATURE
}

\author{
Tomasz DRZYMAŁA ${ }^{1}$, Wioletta JACKIEWICZ-REK ${ }^{2}$, Jerzy GAŁAJ ${ }^{1^{*}}$, Ritoldas ŠUKYS ${ }^{3}$ \\ ${ }^{1}$ Faculty of Fire Safety Engineering, The Main School of Fire Service, \\ Slowackiego St. 52/54, 01-692 Warsaw, Poland \\ ${ }^{2}$ Department of Building Materials Engineering, Faculty of Civil Engineering, \\ Warsaw University of Technology, Al. Armii Ludowej 16, 00-637 Warsaw, Poland \\ ${ }^{3}$ Faculty of Labour Safety and Fire Protection, Vilnius Gediminas Technical University, \\ Sauletekio al. 11, LT-10223 Vilnius, Lithuania
}

Received 30 October 2017; accepted 19 February 2018

\begin{abstract}
There has been a tendency to design ever slender building construction using high strength concrete in recent years. Application of HSC is also growing in tunnel construction. One of the most important challenges is to control explosive spalling of concrete and the method recommended by Eurocode 2 (EN 1992-1-2:2008/NA:2010P) is addition of polypropylene fibres to the mix. The purpose of the research described in this paper was to evaluate the changes of mechanical properties of HSC exposed to the effect of high temperature. The tests were carried out on three types of high strength concrete: air-entrained concrete, polypropylene fibre-reinforced concrete and reference concrete having constant water/cement ratio. The properties of hardened concrete including compressive strength, tensile splitting strength, flexural strength and E-modulus were studied. The latter tests were carried out on both on concrete cured at $20^{\circ} \mathrm{C}$ and concrete subjected to high-temperature conditions at $300{ }^{\circ} \mathrm{C}, 450{ }^{\circ} \mathrm{C}$ and $600^{\circ} \mathrm{C}$. The results enabled us to evaluate the effect of high-temperature conditions on the properties of high-performance concrete and compare the effectiveness of the two methods designed to improve the high-temperature performance of the concrete: addition of polypropylene fibres and entrainment of air.
\end{abstract}

Keywords: high strength concrete, mechanical properties of HSC, high temperature, effect of high temperature.

\section{Introduction}

In terms of fire resistance concrete outperforms by a wide margin the other most popular building materials i.e. wood and steel. Concrete is a non-combustible material, and, as such, it does not increase the fire load and prevents the spread of fire. When exposed to fire temperatures concrete does not release any toxic gases or smoke. However, in fire-simulating high temperature conditions, its internal structure undergoes several physical transformations accompanied with chemical reactions, which result in irrecoverable changes affecting the performance and in the worst case leading to a total destruction of the material.

With no standardized test methods it is difficult to definitively determine the effect of high temperature conditions on concrete. The main cause of such problems is that the respective test methods and regimes use different test parameters including moisture content, age of concrete before exposure, length of time of exposure, rate of tem- perature rise, size and shape of concrete specimens, cooling conditions and the test start point.

Experimental tests to determine the effect of fire/ high temperature conditions are carried out in controlled temperature rate of change conditions represented by temperature-time curves (a.k.a. fire curves). The most popular of them are: standard curve, hydrocarbon curve, external fire exposure curve, tunnel curve (representing the change of temperature during tunnel fires) and slow heating curve. These curves can be found in Bednarek et al. (2010). The fire resistance of concrete structures, as determined in the tests, depends on the rate of temperature rise, as represented by the temperature-time curve such as the standard fire exposure curve used generally in all standard tests.

Another factor influencing the test results is the exposure time, i.e. the time for which concrete is exposed to conditions simulating real-life fire. In order to obtain

${ }^{\star}$ Corresponding author. E-mail: jgalaj@sgsp.edu.pl 
the same temperature throughout the specimen body, the specimens the maximum test temperature is maintained for some additional time - from 40 minutes (Han et al. 2005), through 1 hour (Erdem 2014; Poon et al. 2001) up to the maximum of 3 hours (Behnood, Ghandehari 2009; Noumowe 2005). Although the length of this extra heating time needed to obtain equal temperature throughout the specimen is directly related to the specimen size, such estimates can be inaccurate, thus leading to errors in interpretation of the test results. In the test regime described in this paper the specimen temperature variation is measured directly with the use of insulated thermocouples inserted in the specimen.

The mechanical properties are tested by applying load both directly after exposure (for example to determine residual strength) and after the cooling period (Xiao, König 2004). Higher values were obtained on hot specimens as compared to the results obtained after cooling (Xiao, König 2004; Kowalski 2008).

The properties of concrete exposed to high temperature conditions are considerably influenced by the cooling regime. The specimens were either dry cooled (in air) or wet cooled (quenched) in water (Xiao, König 2004; Kowalski 2008; Husem 2006). Rapid cooling (quenching) was found to have a much more deteriorating effect on the mechanical properties of concrete as compared to dry cooling (Xiao, König 2004; Husem 2006). The differences are particularly pronounced at lower temperatures to become hardly noticeable at the test temperature of $600{ }^{\circ} \mathrm{C}$ (Xiao, König 2004). Similarly, the influence of cooling method (dry or wet) on the mechanical properties of concrete becomes insignificant when the time of quenching is shortened to about $10 \mathrm{sec}$.

The different tests to determine the high temperature performance of concrete use different specimens in terms of shape and size (Behnood, Ghandehari 2009; Noumowe 2005; Drzymała, Bednarek 2011a) with cylindrical specimens expected to enhance obtaining uniform temperature distribution throughout the specimen have been carried out. However, cubes and rectangular prisms of various sizes are also used in such tests (Poon et al. 2001; Arioz 2007; Ergün et al. 2013). It has been demonstrated that the specimen size has no effect on the properties of concrete exposed to high temperature simulating fire conditions.

Also the age of concrete varies between the test procedures used in different research projects. A number of researchers would wait until the material has developed appropriate internal structure, for example after ninety (Hager, Tracz 2008; Pliya et al. 2011) or sixty days (Poon et al. 2001; Ling et al. 2012). With generally accepted 28day curing time (Husem 2006; Biolzi et al. 2008; Saad et al. 1996) such tests were carried out also on very young concrete even one day after moulding (Chen et al. 2009).

Another variable in the high temperature exposure tests is the moisture content of concrete at the time when it is subjected to the elevated temperature simulating fire conditions. It is difficult to control it (in addition to drying to constant weight as we have done in our tests) and main- tain at a constant level and it is hard to obtain repeatability of results in the case of varying moisture content. The tests are very often carried out on specimens cured for 28 days in environmental chamber $\left(20 \pm 2{ }^{\circ} \mathrm{C}, 95 \% \mathrm{RH}\right)$ (Erdem 2014 ) or in air with relative humidity reduced to $60 \%$ (Liu et al. 2008). They are also submerged in water and then kept at laboratory conditions for one day (Han et al. 2005) or even one month (Poon et al. 2001) before subjecting to elevated temperature. It is also quite common to reduce moisture content of concrete by drying the specimens at ca. $105^{\circ} \mathrm{C}$ for 24 hours (Arioz 2007; Saad et al. 1996) or 48 hours (Ergün et al. 2013) before the test.

According to Eurocode 2 (EN 1992-1-2:2008/NA:2010P) and Kowalski (2008) the compressive strength of concrete decreases with the increase of the exposure temperature. This tendency has been confirmed by the result of various research projects (Neville 2012; Drzymała, Bednarek 2011b; Xiao, König 2004). However, the relationship between the compressive strength and the exposure temperature seems to be a more complex. Actually, after slightly decreasing in the range of ca. $100-120{ }^{\circ} \mathrm{C}$ compressive strength returns to the initial level or even rises above it when the concrete is heated to ca. $250{ }^{\circ} \mathrm{C}$ (Hager, Tracz 2008; Biolzi et al. 2008; Chen et al. 2009; Behnood, Ghandehari 2009).

According to EN 1992-1-2:2008/NA:2010P (2010) the tensile strength of concrete exposed to elevated temperature decreases linearly from $100^{\circ} \mathrm{C}$ up to $600^{\circ} \mathrm{C}$ at which it has no tensile strength at all. Actually, while it is true that exposure to elevated temperature affects the tensile strength of concrete, this decrease is not as big as to lead to zero tensile strength at $600{ }^{\circ} \mathrm{C}$ (Neville 2012; Xiao, König 2004; Saad et al. 1996). While according to Neville (2012) the decrease of tensile strength of concrete exposed to elevated temperature follows a similar pattern to the decrease of compressive strength. Many researchers found it to be much greater as compared to the decrease compressive strength, resulting in a considerable increase in brittleness of concrete (Xiao, König 2004; Chen et al. 2009). Exposure to elevated temperature affects also the flexural strength of concrete. The increase in temperature results in a decrease in flexural strength (Husem 2006; Pliya et al. 2011; Ergün et al. 2013).

Exposure to elevated temperature decreases the elasticity of concrete (Neville 2012; Drzymała, Bednarek 2011a, 2011b; Xiao, König 2004; Pliya et al. 2011; Noumowe 2005). According to Neville (2012) the decrease of the modulus of elasticity generally corresponds to the decrease of strength. A simultaneous decrease of the strength and modulus of elasticity with the increase of the temperature of exposure was reported also in Xiao and König (2004); Pliya et al. 2011; Noumowe 2005). Note that the decrease of elasticity is much greater in the case of high-performance concrete as compared to regular concrete (Xiao, König 2004).

\section{Testing plan}

The objective of this research was to determine the effect of elevated temperature on high strength concrete (HSC) 
Table 1. Concrete designs in $\mathrm{kg} / \mathrm{m}^{3}$

\begin{tabular}{|l|c|c|c|}
\hline \multirow{2}{*}{ Concrete ingredients } & \multicolumn{3}{|c|}{ Mix proportions } \\
\cline { 2 - 4 } & HSC - air-entrained & HSC - fibre-reinforced & HSC - reference \\
\hline Cement class CEM I 42.5R, [kg] & 450 & 450 & 450 \\
Water, [kg] & 135 & 135 & 135 \\
0-2 mm sand, [kg] & 732 & 732 & 732 \\
2-8 mm basalt chippings, [kg] & 568 & 568 & 568 \\
8-16 mm basalt chippings, [kg] & 695 & 695 & 695 \\
Superplasticizer, [\% by weight of cement] & 1.75 & 2.33 & 1.75 \\
Air-entraining agent, [\% by weight of cement] & 0.2 & - & - \\
Polypropylene fibres, [kg] & - & 1.5 & - \\
w/c ratio & 0.30 & 0.30 & 0.30 \\
\hline
\end{tabular}

and to assess to what degree its resistance can be improved by addition of polypropylene fibres and entrainment of air. The tests were carried out on the following three types of high performance concrete: air-entrained concrete, polypropylene fibre reinforced concrete and unmodified concrete (control specimens).

The binder used for the tested mixes was Portland cement class CEM I 42.5R. Cement was tested in accordance with EN 197-1:2012P (2012). According to the test results the chosen type of cement is appropriate for the mixes. River sand was used as fine aggregate and 2/8 and 8/16 mm basalt as coarse aggregate. Sand equivalent (SE) was taken at $37 \%$. The grading curve was within the grading envelope as defined by the Polish Standard PN-88/B-06250 (1988). Modified polycarboxylate superplasticizer was added to obtain the specified slump class (S3). Air-entraining agent was added to the air-entrained concrete mix (4-5\% with appropriate internal structure i.e. size and spatial distribution of voids) and polypropylene fibres were added at a rate of $1.5 \mathrm{~kg} / \mathrm{m}^{3}$ to produce fibre reinforced concrete. For the concrete designs see Table 1 .

The tests were carried out both at the ambient temperature of $20^{\circ} \mathrm{C}$ and after exposure of specimens to elevated temperatures of $300{ }^{\circ} \mathrm{C}, 450{ }^{\circ} \mathrm{C}$ and $600{ }^{\circ} \mathrm{C}$. The experiments included testing the properties of fresh concrete, such as: consistency, maximum density and total air voids as well as the properties of hardened concrete, such as: compressive strength, tensile splitting strength, flexural strength and elasticity.

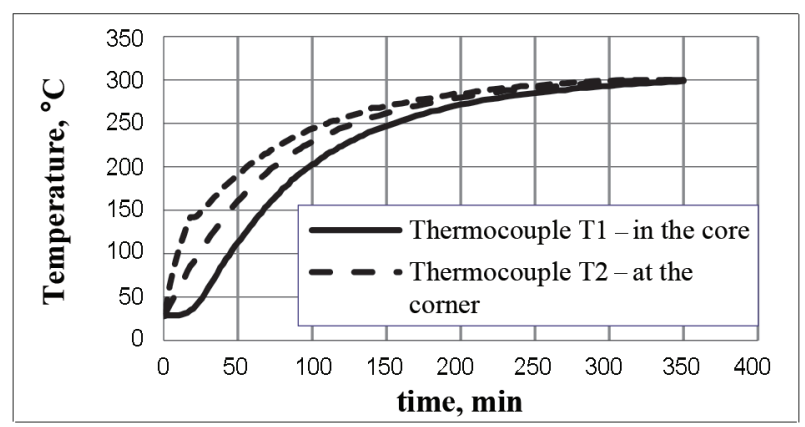

Figure 1. Example of heat treatment set-up at $300{ }^{\circ} \mathrm{C}$ using $150 \mathrm{~mm}$ cubes
Before exposure to elevated temperature $\left(300{ }^{\circ} \mathrm{C}\right.$, $450{ }^{\circ} \mathrm{C}$ and $600{ }^{\circ} \mathrm{C}$ respectively) the specimens were cured for 28 days and then removed from the chamber. Next they were dried to a constant weight in forced air ovens at $105^{\circ} \mathrm{C}$ for another seven days. Then the specimens were taken out from the ovens and holes for inserting thermocouples were drilled to monitor the internal temperature. A special test facility was used for this purpose including PK 1100/5 medium-temperature electric chamber furnace and PC class computer with installed software to control the process and record the temperature during heat treatment (Figure 1).

The specimens were placed on the furnace bottom on fire clay slabs apart from one another and from the heating surfaces of the furnace. For reliable monitoring of the internal temperature the reference specimens were always placed in the center (Figure 2).

The heat treatment process followed the standard fire exposure curve according to ISO 834 (1985) and EN 19921-2:2008/NA:2010P (2010). The transfer of heat was monitored at three points on each specimen (Figure 3 ).

\section{Presentation and analysis of the test results}

The characteristic values measured at different values of temperature on fresh and hardened concrete were included in Table 2.

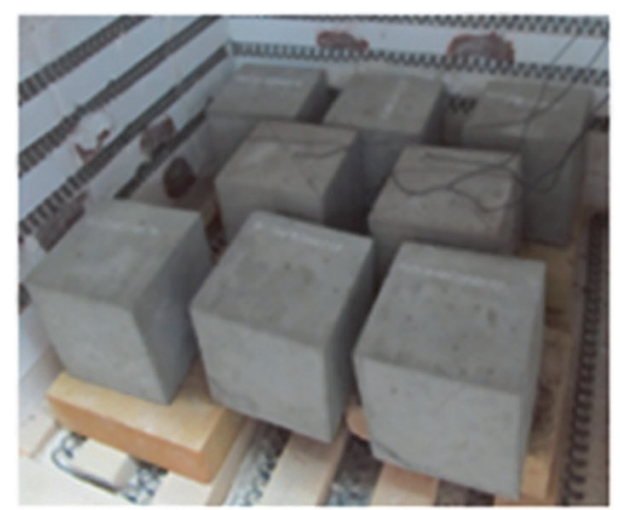

Figure 2. Arrangement of specimens inside the furnace 

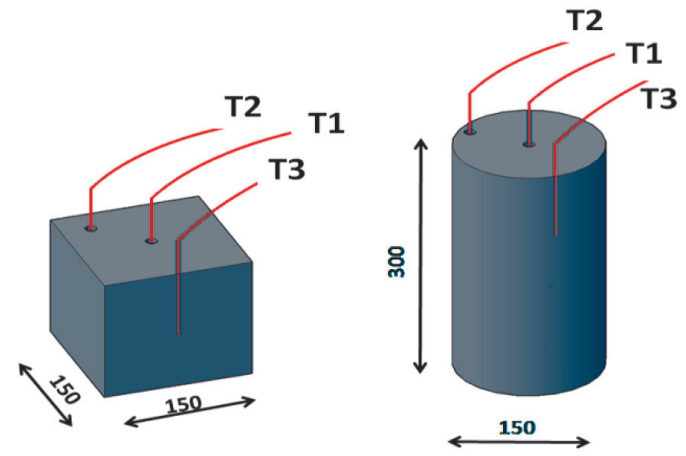

Figure 3. Siting of the thermocouples in concrete cubes: $\mathrm{T} 1$ - in the core, $\mathrm{T} 2$ - at the corner $3 \mathrm{~cm}$ from edges and halfway through the height, T3 - on the side surface halfway through the height; and concrete cylinders: $\mathrm{T} 1$ - in the core, $\mathrm{T} 2$ - at the corner $3 \mathrm{~cm}$ from the edge at $1 / 4$ the height, T3 on the side surface at $1 / 4$ the height (all dimensions in $\mathrm{mm}$ )

In the initial curing time i.e. in the first 28 days from casting, all the concrete types had very similar compressive strength. The differences between the respective concrete types were about $5.5 \%$. Air-entrainment of one concrete type did not have a noticeable effect on its compressive strength.

After 28 days of curing all concretes met the compressive strength criterion for C55/67 class, tested according to PN-EN 206:2014-04 (2014), thus classifying as highperformance concrete. Heating at $300{ }^{\circ} \mathrm{C}$ increased the compressive strength in relation to the initial value determined at $20{ }^{\circ} \mathrm{C}$ in the case of air-entrained and fibre-reinforced concretes. With a further increase in the temperature a drop of compressive strength was noted for all the tested types of concrete. It should be noted that at $450{ }^{\circ} \mathrm{C}$ the compressive strength of HSC was either higher than (in the case of air-entrained and reference samples) or almost the same (in the case of fibre-reinforced concrete) as the value measured at $20^{\circ} \mathrm{C}$. The compressive strength dropped off after heating at $600{ }^{\circ} \mathrm{C}$ - to $75 \%$ of the initial value in the case of air-entrained HSCHSC, to $65 \%$ in the case of fibre-reinforced HSC and to $82 \%$ in the case of reference concrete.

Air-entrainment reduces the compressive strength of high-performance concrete by ca. $17 \%$ in relation to reference concrete, as measured on the specimens after 180 days from casting, giving on average $6.3 \%$ decrease per one percent air content in the mix.

Figure 4 compares the test results with the decrease of strength predicted for $\mathrm{C} 55 / 67$ concrete by Eurocode 2 (EN 1992-1-2:2008/NA:2010P) in relation to the temperature of exposure. As it can be seen on Figure 5, EN 19921-2:2008/NA:2010P (2010) does not consider the increase of compressive strength of C 55/67 class concrete after exposure to elevated temperature. This relationship is challenged by the results obtained under this research where all the types of concrete exhibited increase in compressive

Table 2. The measured values of properties

\begin{tabular}{|c|c|c|c|c|c|}
\hline \multicolumn{6}{|c|}{ Fresh concrete mix } \\
\hline \multicolumn{3}{|c|}{ Consistency - slump class } & S3 & S3 & S3 \\
\hline \multicolumn{3}{|c|}{ Density $\left[\mathrm{g} / \mathrm{cm}^{3}\right]$} & 2.570 & 2.530 & 2.600 \\
\hline \multicolumn{3}{|c|}{ Air content [\%] } & $4.2-4.8$ & $\leq 2$ & $\leq 2$ \\
\hline \multicolumn{6}{|c|}{ Hardened concrete } \\
\hline Properties & Temperature $\left[{ }^{\circ} \mathrm{C}\right]$ & Age [days] & HSC - air-entrained & HSC - fibre-reinforced & HSC - reference \\
\hline \multirow{7}{*}{$\begin{array}{l}\text { Compressive strength } \\
{[\mathrm{MPa}]}\end{array}$} & 20 & 2 & 52.5 & 51 & 54.5 \\
\hline & 20 & 28 & 76.9 & 74.7 & 72.7 \\
\hline & 20 & 90 & 77.7 & 80.6 & 83.5 \\
\hline & 20 & 180 & 80.4 & 91.1 & 97.2 \\
\hline & 300 & 28 & 85.0 & 78.4 & 88.5 \\
\hline & 450 & 28 & 82.7 & 74.4 & 81.8 \\
\hline & 600 & 28 & 58.0 & 48.2 & 59.3 \\
\hline \multirow{4}{*}{$\begin{array}{l}\text { Tensile splitting } \\
\text { strength, } \\
\text { [MPa] }\end{array}$} & 20 & 28 & 4.16 & 4.86 & 4.27 \\
\hline & 300 & 28 & 3.87 & 4.54 & 4.49 \\
\hline & 450 & 28 & 3.35 & 3.68 & 3.91 \\
\hline & 600 & 28 & 1.85 & 1.50 & 1.85 \\
\hline \multirow{2}{*}{$\begin{array}{l}\text { Flexural strength, } \\
{[\mathrm{MPa}]}\end{array}$} & 20 & 28 & 5.60 & 6.96 & 6.51 \\
\hline & 300 & 28 & 4.97 & 5.42 & 6.14 \\
\hline \multirow{4}{*}{$\begin{array}{l}\text { Modulus of elasticity, } \\
{[\mathrm{MPa}]}\end{array}$} & 20 & 28 & 44.96 & 47.742 & 49.75 \\
\hline & 300 & 28 & 31.98 & 32.246 & 32.79 \\
\hline & 450 & 28 & 21.98 & 17.791 & 20.78 \\
\hline & 600 & 28 & 8.055 & 7.224 & 8.168 \\
\hline
\end{tabular}




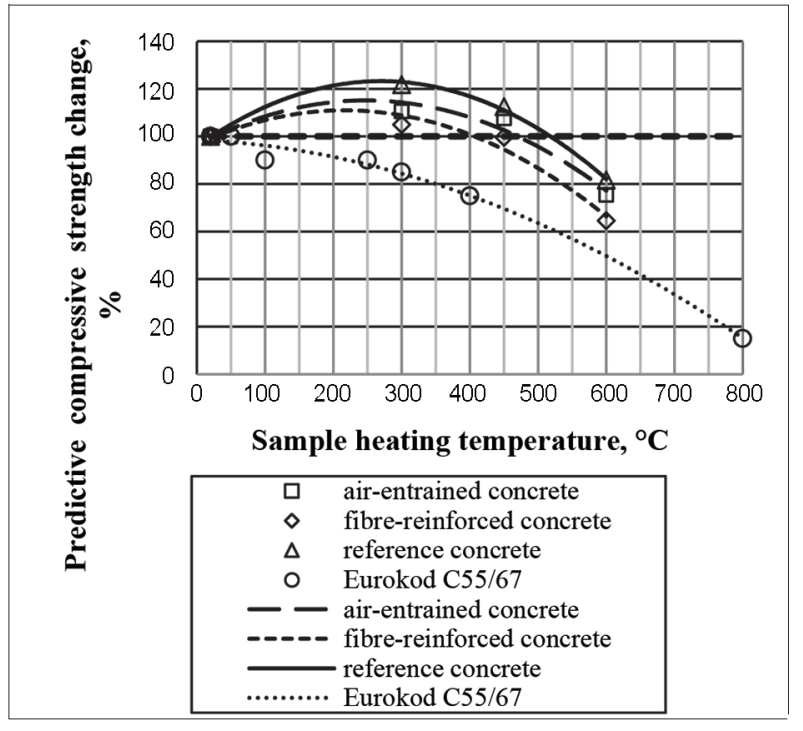

Figure 4. Compressive strength vs heating temperature according to Eurocode 2 (EN 1992-1-2:2008/NA:2010P) and test results

strength after heating at $300{ }^{\circ} \mathrm{C}$ and had the same compressive strength as the reference (unexposed) specimens after heating at $450{ }^{\circ} \mathrm{C}$ rather than $70 \%$ of the initial value as predicted according to the standard. Moreover, fibrereinforced concrete - the weakest of all - after exposure to $600{ }^{\circ} \mathrm{C}$ retained $65 \%$ of its initial compressive strength as compared to some $50 \%$ as predicted by the standard. This demonstrates that the standard (EN 1992-1-2:2008/ NA:2010P) assumes a very conservative approach in estimating the residual compressive strength of concrete exposed to fire.

Among the tested high-performance concretes the fibre-reinforced concrete had the highest initial tensile splitting strength at $20^{\circ} \mathrm{C}$, which confirms the improving effect of polypropylene fibres. After heating the specimens at $300{ }^{\circ} \mathrm{C}$ a $7 \%$ decrease was noted in the average tensile splitting strength, both in the case of fibre-reinforced and air-entrained concretes. On the other hand, a slight,

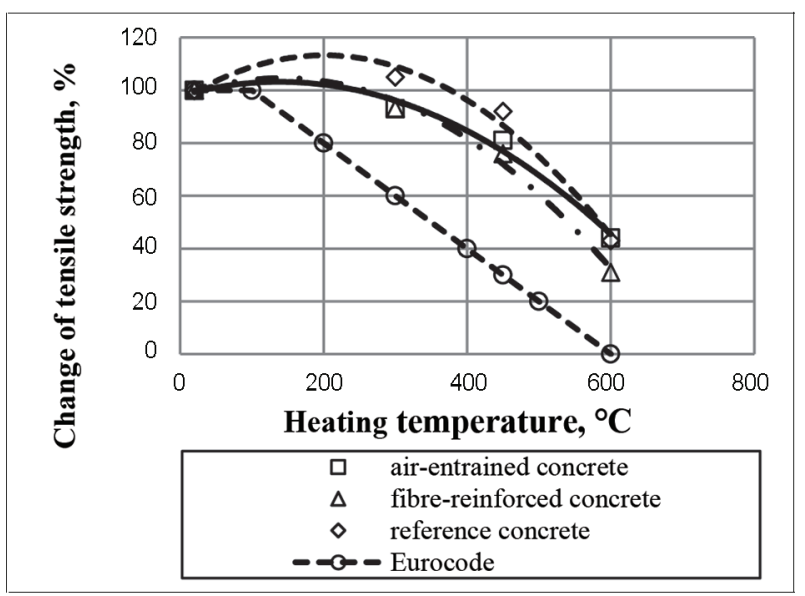

Figure 5. Tensile strength vs heating temperature according to Eurocode 2 (EN 1992-1-2:2008/NA:2010P) and test results namely $5 \%$ increase was observed in the case of reference concrete. Moreover, fibre-reinforced concrete had still the highest tensile strength of all, meaning that at $300^{\circ} \mathrm{C}$ fibres had an improving effect on this property. However, a further increase in the temperature affected all the concretes and the drop becomes considerable at $600{ }^{\circ} \mathrm{C}$. The fibrereinforced concrete after this temperature had the lowest tensile strength among all the tested concrete due to the process of pyrolysis of polypropylene fibres damaging the internal structure of the material.

EN 1992-1-2:2008/NA:2010P (2010) suggests to ignore the tensile strength while designing concretes structures which may become exposed to elevated temperature and when the tensile strength must be considered it should be adjusted with the estimated decrease of tensile strength after exposure (Figure 5).

As it can be seen from Figure 5 the European standard EN 1992-1-2:2008/NA:2010P (2010) is very conservative also in this case i.e. by predicting a linear drop of the tensile strength with the increasing temperature of exposure. However, the experimental results obtained allow us to find that this decrease of tensile strength with the increase of temperature is neither linear nor as big as predicted according to the standard. Note that heating at $300^{\circ} \mathrm{C}$ resulted in a $7 \%$ decrease of tensile strength in two cases, i.e. in the case of air-entrained and fibre-reinforced concrete - as compared to the value of $40 \%$ implied by the standard. According to Eurocode heating at $450^{\circ} \mathrm{C}$ should decrease the tensile strength of concrete to $30 \%$ of the strength determined at $20^{\circ} \mathrm{C}$, which, however, was not confirmed by our testing in which the lowest residual tensile strength was $76 \%$, measured on fibre-reinforced concrete.

Moreover, according to the standard after heating at $600{ }^{\circ} \mathrm{C}$ should have no tensile strength at all. It was not confirmed by the results of our tests in which we obtained $31 \%$ residual strength for fibre-reinforced concrete and over $40 \%$ for air-entrained and reference concrete.

As it can be seen from the Figure 6, subjecting concrete to fire temperatures increases brittleness considerably. This questioning the relationship between compressive and tensile strength. In tests, the increase in compressive strength was not accompanied by a simultaneous increase in the tensile strength.

After 28 days of curing in the environmental chamber fibre-reinforced concrete was found to have the highest flexural strength. This fact demonstrates that addition of polypropylene fibres is beneficial to this property of concrete, the same as in the case of tensile strength.

After heating at $300{ }^{\circ} \mathrm{C}$ the greatest percentage drop in flexural strength in relation to reference (unexposed) specimens was $22 \%$ observed in the case of the fibre reinforced concrete, followed by air-entrained concrete with $11 \%$ drop. The values of flexural strength in the order of $5 \mathrm{MPa}$, as were obtained for all the types of concrete heated at $300{ }^{\circ} \mathrm{C}$ are considered satisfactory and allow for a wide range of structural applications of the tested concretes.

Exposure to elevated temperature considerably decreased the modulus of elasticity of all the tested types of 


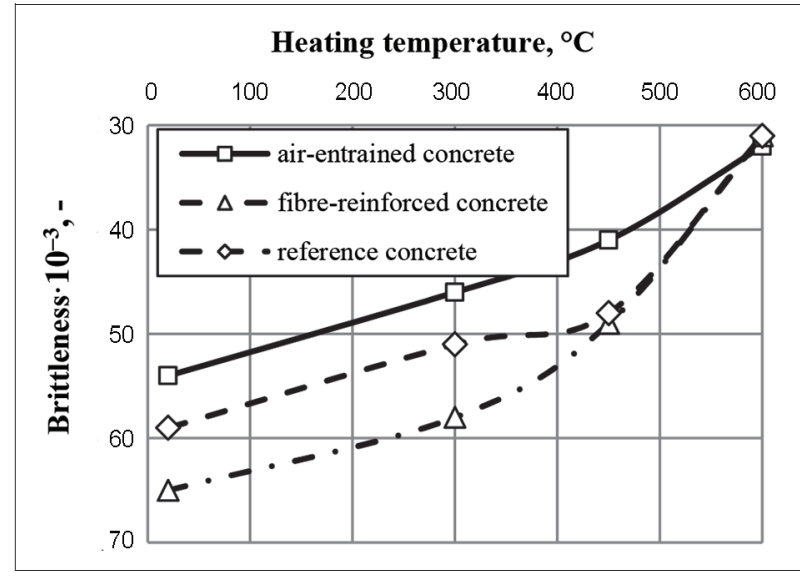

Figure 6. Brittleness of high-performance concrete vs temperature of exposure

concrete (Figure 7). Increase of the temperature of heating resulted in an almost linear decrease of this parameter. Virtually the same moduli were obtained for all tested types of concrete after heating at $300{ }^{\circ} \mathrm{C}$ and $600{ }^{\circ} \mathrm{C}$. The only exception to that was exposure to $450{ }^{\circ} \mathrm{C}$ which resulted in a $12 \%$ difference between the highest and lowest values obtained for air-entrained concrete and fibre-reinforced concrete respectively. Attention is drawn to a sharp drop in the value of the modulus of elasticity after heating at $600{ }^{\circ} \mathrm{C}$ to only $15-18 \%$ of the value determined on the reference specimens. This indicates a high sensitivity of this parameter to heating at fire temperatures.

The modulus of elasticity of concrete is related to its compressive strength. Very often the higher is the compressive strength the higher the modulus of elasticity of concrete. The results of tests show, however, that this relationship should rather not be applied unconditionally to concrete subjected to the effect of elevated temperature. This is particularly important when estimating the modulus of elasticity of concrete after fire on the basis of measured compressive strength. Figure 8 present the percentage changes of compressive strength and modulus of elasticity in relation to the values obtained on the reference (unexposed) specimens vs heating temperature for all tested types of concrete.

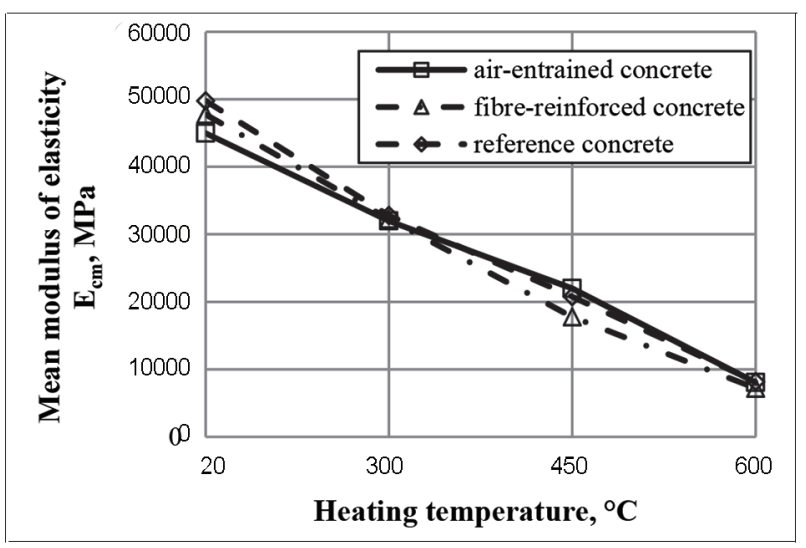

Figure 7. Modulus of elasticity vs heating temperature for all tested concretes

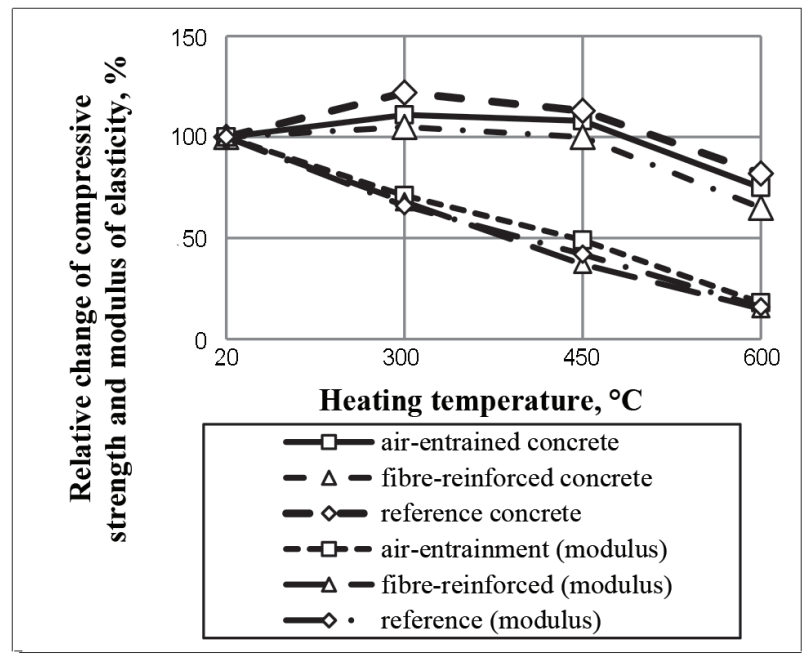

Figure 8. Compressive strength and elasticity modulus in relation to the reference (unexposed) specimens vs heating temperature for all tested types of concrete

Figure 8 clearly shows the difference between the relationships of these two parameters versus the temperature of exposure. The increase of compressive strength at $300^{\circ} \mathrm{C}$ is accompanied with a clear drop in the modulus of elasticity. Increasing of the heating temperature to $450{ }^{\circ} \mathrm{C}$ resulted in a drop in the compressive strength for all tested types of concrete in relation to the results obtained after heating at $300{ }^{\circ} \mathrm{C}$ accompanied by a further drop in the modulus of elasticity.

Nonetheless, compressive strength was in all cases at least equal to the value obtained on unexposed specimens while the highest value of the modulus of elasticity, obtained on air-entrained concrete, equalled $49 \%$ of the value obtained for this type of concrete at $20^{\circ} \mathrm{C}$. At $600^{\circ} \mathrm{C}$ the compressive strength was lower than the value obtained at $20{ }^{\circ} \mathrm{C}$. Still it remained at an acceptable level even in the case of fibre-reinforced concrete for which the greatest decrease of strength was noted after heating at $600{ }^{\circ} \mathrm{C}$, i.e. $65 \%$ of the strength determined on unexposed specimens. At the highest heating temperature the modulus of elasticity dropped to $15-18 \%$ of the value obtained at $20^{\circ} \mathrm{C}$ for all tested types of concrete.

Exposure of polypropylene fibre reinforced HSC to elevated temperature approximating the fire conditions decreased its modulus of elasticity. Concrete including polypropylene fibres exhibits a slightly higher modulus of elasticity as compared to concrete without such addition.

\section{Conclusions}

Heating at $300{ }^{\circ} \mathrm{C}$ increases the compressive strength of high-performance concrete in relation to the initial strength determined at $20^{\circ} \mathrm{C}$, which was observed on all tested types of high-performance concrete: air-entrained, fibre-reinforced and reference specimens. At $450{ }^{\circ} \mathrm{C}$ compressive strength decreased in all cases in relation to the value determined after heating at $300{ }^{\circ} \mathrm{C}$, though it did not drop below the initial value. Heating at $600{ }^{\circ} \mathrm{C}$ reduced 
the compressive strength below the value determined on unexposed specimens in all cases with the maximum drop to $65 \%$ of the initial value noted for the fibre-reinforced concrete.

Exposure of high-performance concrete to the elevated temperature of $300{ }^{\circ} \mathrm{C}$ affected the tensile splitting strength of air-entrained concrete and fibre-reinforced concrete while slightly improving this parameter in the case of reference concrete (as compared to the initial value determined at $20^{\circ} \mathrm{C}$ ). However, after heating at $450^{\circ}$ also the reference concrete exhibited a decreased tensile splitting strength and a further slight decrease was noted in the case of the other types of concrete, i.e. air-entrained and fibre-reinforced high-performance concrete. After heating at $600{ }^{\circ} \mathrm{C}$ a sharp decrease in the tensile strength was noted for all the tested types of concrete. The lowest residual strength of $31 \%$ was measured on fibre-reinforced concrete specimens.

After exposure to the temperature approximating fire conditions a decrease in elasticity was noted for air-entrained, fibre-reinforced and reference concrete. An almost linear relationship between the decrease in the modulus of elasticity and the increase of heating temperature can be observed. After heating at $600{ }^{\circ} \mathrm{C}$ the modulus was in the range of $15-18 \%$ of the value determined on unexposed specimens.

\section{References}

Arioz, O. 2007. Effects of elevated temperatures on properties of concrete, Fire Safety Journal 42(8): 516-522. https://doi.org/10.1016/j.firesaf.2007.01.003

Bednarek, Z.; Ogrodnik, P.; Pieniak, D. 2010. Laboratory method of evaluation of influence high temperatures on maintenance parameters of the reinforced concrete systems compound, Eksploatacja i niezawodność 47(3): 67-78.

Behnood, A.; Ghandehari, M. 2009. Comparison of compressive and splitting tensile strength of high-strength concrete with and without polypropylene fibers heated to high temperatures, Fire Safety Journal 44(8): 1015-1022. https://doi.org/10.1016/j.firesaf.2009.07.001

Biolzi, L.; Cattaneo, S.; Rosati, G. 2008. Evaluating residual properties of thermally damaged concrete, Cement \& Concrete Composites 30(10): 907-916.

https://doi.org/10.1016/j.cemconcomp.2008.09.005

Chen, B.; Li, C.; Chen, L. 2009. Experimental study of mechanical properties of normal-strength concrete exposed to high temperatures at an early age, Fire Safety Journal 44(7): 9971002. https://doi.org/10.1016/j.firesaf.2009.06.007

Drzymała, T.; Bednarek, Z. 2011a. Analysis of the values of modulus of elasticity measured after exposure to elevated temperature of high-performance concrete reinforced with polypropylene fibres, Logistyka 6 (in Polish).

Drzymała, T.; Bednarek, Z. 2011b. Chosen prospects for use of polypropylene fibre reinforced concrete in applications involving exposure to high temperature, Logistyka 6 (in Polish).

EN 1992-1-2:2008/NA:2010P, Eurocode 2: Design of concrete structures. Parts 1-2: General rules. Structural fire design. European Standards Committee, 2010.

EN 197-1:2012P. Cement. Part 1: Cement. Composition, specifications and conformity criteria for common cements. European Standards Committee, 2012.
EN 206:2014-04. Concrete - Specification, performance, production and conformity. European Standards Committee, 2014.

Erdem, T. K. 2014. Specimen size effect on the residual properties of engineered cementitious composites subjected to high temperatures. Cement and Concrete Composites 45: 1-8. https://doi.org/10.1016/j.cemconcomp.2013.09.019

Ergün, A.; Kürklü, G.; Başpınar, M. S.; Mansour, M. Y. 2013. The effect of cement dosage on mechanical properties of concrete exposed to high temperatures, Fire Safety Journal 55: 160167. https://doi.org/10.1016/j.firesaf.2012.10.016

Hager, I.; Tracz, T. 2008. The effect of elevated temperature on the selected properties of high-performance concrete reinforced with rolypropylene fibres, in Concrete Days Conference in Wisła, 2008, Poland (in Polish).

Han, C.-G.; Hwang, Y.-S.; Yang, S.-H.; Gowripalan, N. 2005. Performance of spalling resistance of high performance concrete with polypropylene fibre contents and lateral confinement, Cement and Concrete Research 35(9): 1747-1753. https://doi.org/10.1016/j.cemconres.2004.11.013

Husem, M. 2006. The effects of high temperature on compressive and flexural strengths of ordinary and high-performance concrete, Fire Safety Journal 41(2): 155-163. https://doi.org/10.1016/j.firesaf.2005.12.002

ISO 834 Fire resistance test elements of building construction. Geneva: International Organization for Standardization, 1985.

Kowalski, R. 2008. Computational evaluation of reinforced concrete components loaded in bending under fire conditions. Warsaw: Warsaw Polytechnic Publishing House (in Polish).

Ling, T.-C.; Poon, C.-S.; Kou, S.-C. 2012. Influence of recycled glass content and curing conditions on the properties of selfcompacting concrete after exposure to elevated temperatures, Cement and Concrete Composites 34(2): 265-272.

https://doi.org/10.1016/j.cemconcomp.2011.08.010

Liu, X.; Ye, G.; De Schutter, G.; Yuan, Y.; Taerwe, L. 2008. On the mechanism of polypropylene fibres in preventing fire spalling in self-compacting and high performance cement paste, Cement and Concrete Research 38(4): 487-499. https://doi. org/10.1016/j.cemconres.2007.11.010

Neville, A. M. 2012. Properties of concrete. Cracow: Polski Cement.

Noumowe, A. 2005. Mechanical properties and microstructure of high strength concrete containing polypropylene fibres exposed to temperatures up to $200{ }^{\circ} \mathrm{C}$, Cement and Concrete Research 35(11): 2192-2198.

https://doi.org/10.1016/j.cemconres.2005.03.007

Pliya, P.; Beaucour, A-L.; Noumowé, A. 2011. Contribution of cocktail of polypropylene and steel fibres in improving the behaviour of high strength concrete subjected to high temperature, Construction and Building Materials 25(4): 1926-1934. https://doi.org/10.1016/j.conbuildmat.2010.11.064

PN-88/B-06250 Beton zwykty [Plain concrete]. Polish standard, 1988.

Poon, C.-S.; Azhar, S.; Anson, M.; Wong, Y.-L. 2001. Comparison of the strength and durability performance of normal- and high-strength pozzolanic concretes at elevated temperatures, Cement and Concrete Research 31(9): 1291-1300.

https://doi.org/10.1016/S0008-8846(01)00580-4

Saad, A.; Abo-El-Enein, S. A.; Hanna, G. B.; Kotkata, M. F. 1996. Effect of temperature on physical and mechanical properties of concrete containing silica fume, Cement and Concrete Research 26(5): 669-675. https://doi.org/10.1016/S0008-8846(96)85002-2

Xiao, J.; König, G. 2004. Study on concrete at high temperature in China - an overview, Fire Safety Journal 39(1): 89-103. https://doi.org/10.1016/S0379-7112(03)00093-6 